Spring 4-28-2020

\title{
An Occupational Therapy Approach to Education for Foster Parents
}

Alexandra E. Judd

University of St. Augustine for Health Sciences

DOI: https://doi.org/10.46409/sr.GUVH6953

Follow this and additional works at: https://soar.usa.edu/capstones

Part of the Family, Life Course, and Society Commons, Occupational Therapy Commons, and the Social Work Commons

\section{Recommended Citation}

Judd, A. E. (2020). An Occupational Therapy Approach to Education for Foster Parents. [Doctoral project, University of St Augustine for Health Sciences]. SOAR @ USA: Student Capstone Projects Collection. https://doi.org/10.46409/sr.GUVH6953

This Capstone is brought to you for free and open access by the Student Research at SOAR @ USA. It has been accepted for inclusion in Student Capstone Projects by an authorized administrator of SOAR @ USA. For more information, please contact soar@usa.edu, erobinson@usa.edu. 


\section{AN OCCUPATIONAL THERAPY APPROACH TO EDUCATION FOR FOSTER PARENTS}

by

Alexandra E. Judd

A Capstone Presented in Partial Fulfillment

of the Requirement for the Degree of

DOCTOR OF OCCUPATIONAL THERAPY

University of St. Augustine for Health Sciences

April, 2020 


\title{
AN OCCUPATIONAL THERAPY APPROACH TO EDUCATION FOR FOSTER PARENTS
}

\author{
by
}

\author{
Alexandra E. Judd \\ has been approved
}

April, 2020

APPROVED:

Susan MacDermott, OTD, OTR/L, Doctoral Coordinator

Becki Cohill, OTD, OTR/L, Doctoral Coordinator

Erin Schwier, EdD, OTD, OTR/L, Program Director

ACCEPTED AND SIGNED:

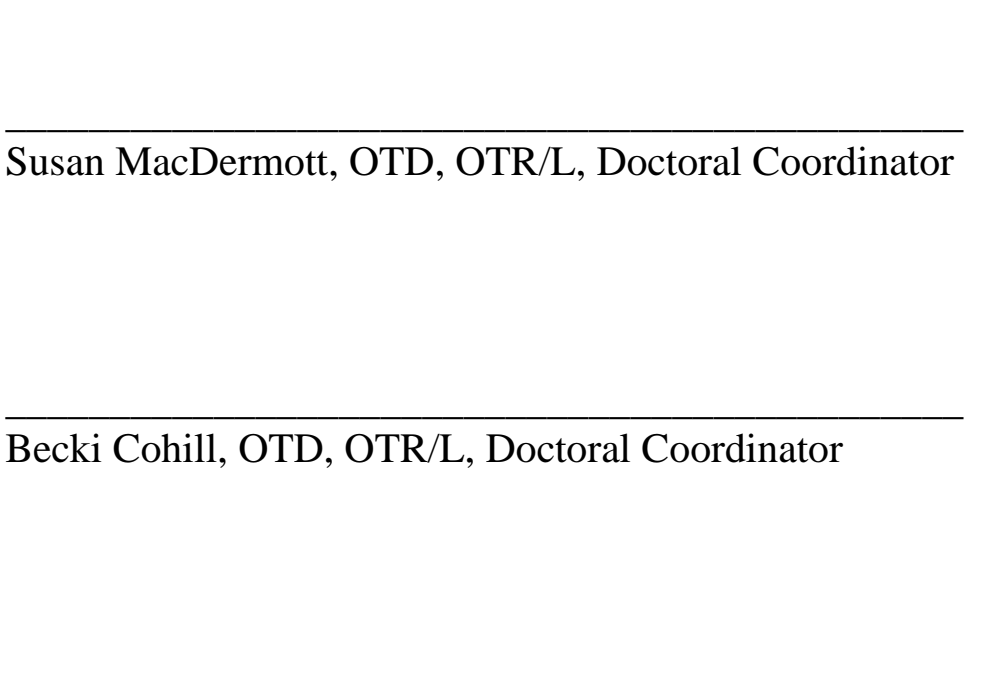

Erin Schwier, EdD, OTD, OTR/L, Program Director 
Table of Contents

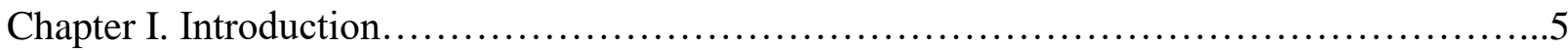

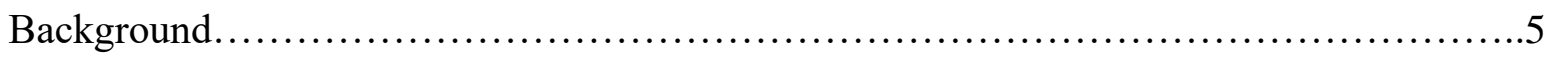

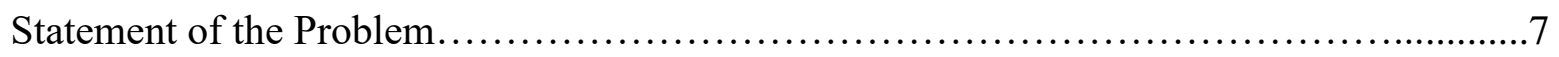

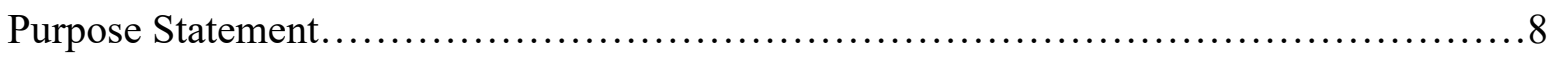

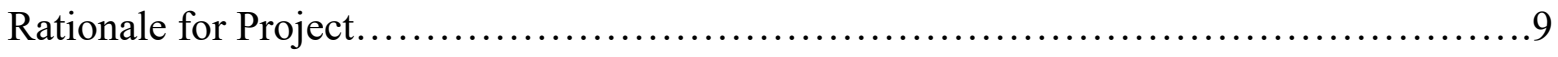

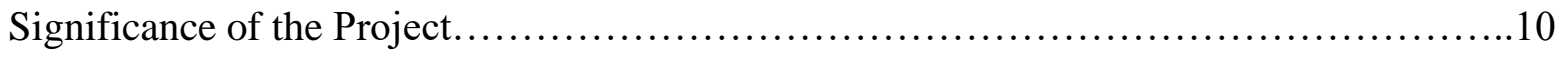

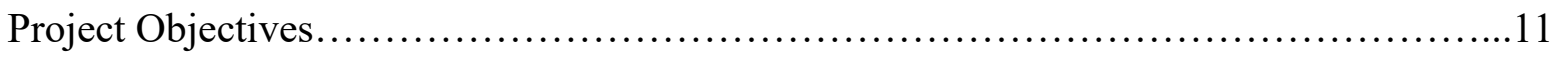

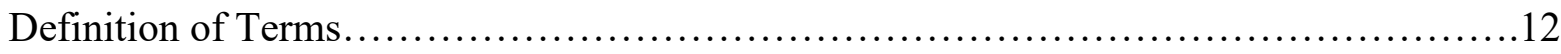

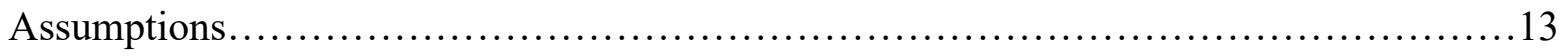

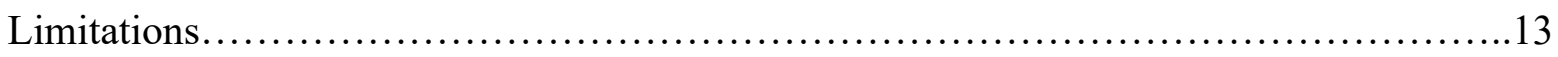

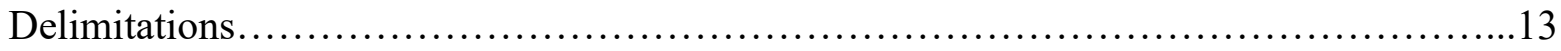

Chapter II. Literature Review......................................................... 14

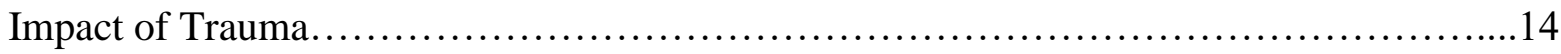

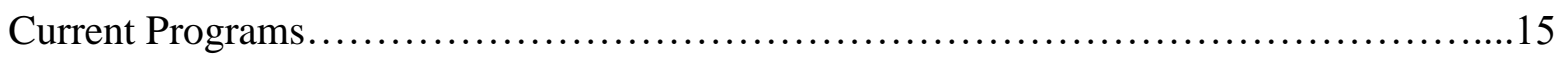

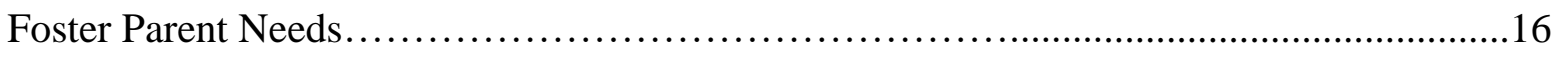

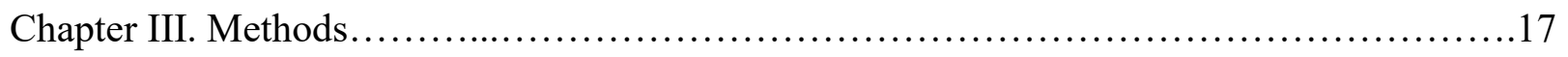

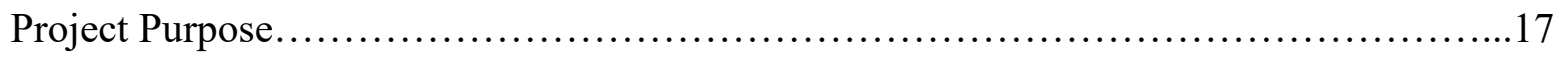

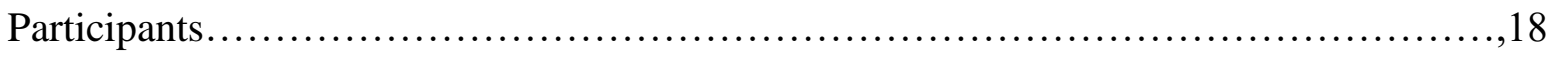

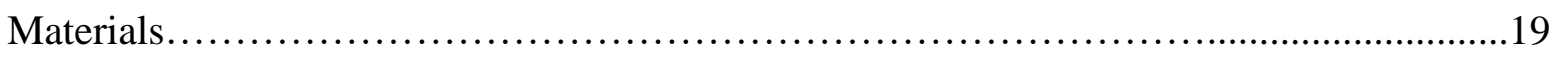

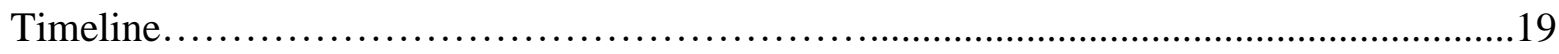

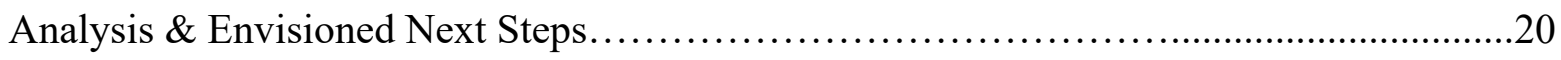

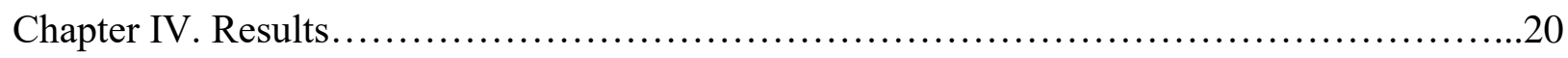

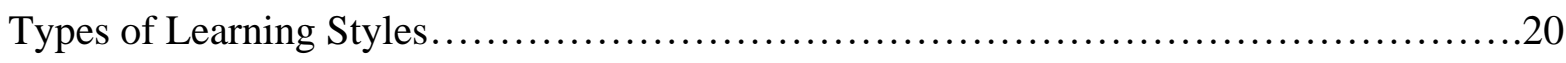




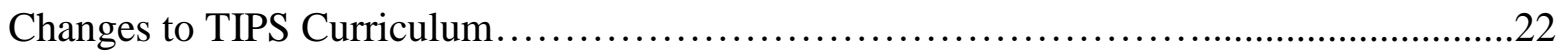

Strengths of TIPS Classes.....................................................23

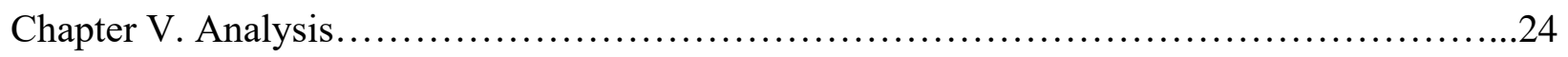

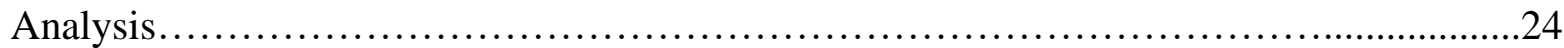

Chapter VI. Summary, Discussions, and Conclusions................................26

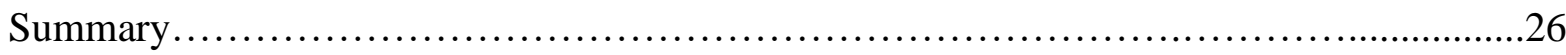

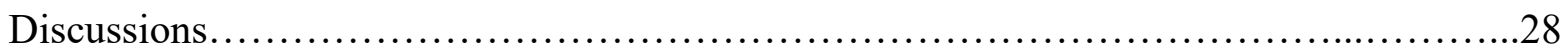

Conclusions............................................................29

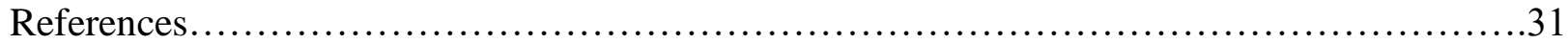

Appendix A - Semi-Structured Interview ............................................

Appendix B - Handout with Suggestions for Curriculum Enhancement.....................39

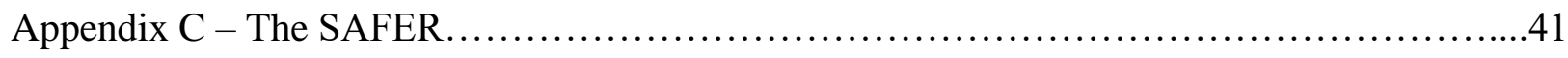

Appendix D - The Parental Stress Scale.............................................49 


\section{Chapter I. Introduction}

\section{Background}

According to the 2016 Adoption and Foster Care Analysis and Reporting System (AFCARS), an estimated 437,500 children between the ages of birth to 20 -years-old were in foster care at the end of the 2016 fiscal year; this number has continued to rise since 2012 (U.S. Department of Health and Human Services, 2017). The increasing number of youths in foster care need more out-of-home housing options.

Current evidence shows that an overwhelming majority of children in the foster care system have experienced multiple traumas: an estimated $95 \%$ of children in the foster system experienced a suspected traumatic event and $75 \%$ experienced an actionable traumatic event, which is defined as a significant traumatic event experienced by the child (Beyerlein \& Bloch, 2014; Griffin et al., 2011). The most common types of trauma experienced by children in the foster system include neglect, family violence, traumatic grief/separation, physical abuse, emotional abuse, sexual abuse, and witness to criminal activity (Griffin et al., 2011).

When children experience trauma at a young age, it can have an impact on their development in physical, emotional/psychological, intellectual, and social development (Fratto, 2016). Delays in these developmental areas may cause a child to display atypical behaviors that foster parents perceive as challenging, including an inability to sleep, bed wetting, a consistent sense of fear, stomach aches, attention deficit hyperactivity disorder (ADHD), and difficulty with concentration (Beyerlein \& Bloch, 2014). Challenging behaviors may lead children to experience placement instability because foster parents feel ill equipped to support the needs of children who experience trauma (Hebert \& Kulkin, 2018). Placement instability due to challenging 
behavior is associated with difficulty in school, lower self-esteem, and overall reduced life satisfaction in foster youth (Bederian-Gardner et al., 2018).

Foster parents report wanting more training in the areas of managing challenging behaviors and helping children adjust to the home to improve placement stability for foster youth (Hebert \& Kulkin, 2018). The implementation of evidence-based foster parent training intervention can help increase a foster parent's confidence in managing challenging behaviors, can help increase the chance of a positive placement change (e.g., reunion with biological parents or adoption), and can decrease the risk of a child experiencing multiple placements (Price, Chamberlain, Landsverk, \& Reid, 2009). Due to a lack of trauma screening, childhood trauma often goes untreated (Bederian-Gardner et al., 2018; Beyerlein \& Bloch, 2014; Fratto, 2016). In addition to the children themselves, the community is also affected by untreated childhood trauma in the foster system. Families, schools, community agencies, and taxpayers are affected via the billions of dollars per year spent on related consequences of untreated childhood trauma (Beyerlein \& Bloch, 2014).

Occupational therapy does not serve foster youth directly through the foster system. Foster youth receive occupational therapy services through the school system where the occupational therapist advocates for an individualized education program to meet the specific needs of the child and ensure that the school understands how the child's academic performance may be affected by trauma; these children can also receive community-based or medically-based services to treat developmental delays or underlying medical conditions (Lamb et al., 2017). Children with special education needs receive services regulated under the Individuals with Disabilities Education Act (IDEA) Part B. Under Part B of IDEA, occupational therapy is a related service and is provided to assist children with special education needs to succeed in 
school (American Occupational Therapy Association [AOTA], n.d.-b). In order to be eligible for occupational therapy services in schools, students must qualify for and receive special education services (AOTA, n.d.-b). Not all foster youth qualify for special education services, leaving many unserved in the school setting.

Occupational therapists also see foster youth in a clinic-based setting to address developmental delays and to increase independence in meaningful occupations for the child. The clinic services are funded through the child's insurance provider, which is typically Medicaid for children in foster care (Children's Bureau, n.d.). Traditional occupational therapy services with this population do not include providing trauma education to foster parents or educating them on how trauma can influence occupational performance and engagement.

\section{Statement of the Problem}

Children in the foster care system who experience trauma may fall into a repetitive cycle of displaying challenging behaviors, causing them to lose their placement because foster parents feel unprepared to manage such behaviors (Price et al., 2009). After children experience a loss of placement, they are likely to display more challenging behaviors, making them more likely to experience placement instability (Lee, Choi, Lee, \& Kramer, 2017). Research suggests that implementing an evidence-based training program for foster parents may help increase placement stability, thereby decreasing the emotional trauma the child experiences and reducing the financial burden experienced by the taxpayers and the community (Goldhaber-Fiebert et al., 2012; Price et al., 2009). However, there is no federal regulation regarding the training and intervention that foster parents receive prior to receiving their foster care license or as part of the continuing education requirements after receiving their foster care license; there are only national recommendations from the Foster Family Based Treatment Association that were last updated in 
2004 (Dorsey et al., 2008). These recommendations include a course on the signs and symptoms of child abuse, but nothing relating to the impact of experiencing trauma on a child's behaviors or occupational engagement is included (Dorsey et al., 2008).

Trauma can impact a child's ability to perform age-expected occupations. Children who experience trauma can become "stuck" in their neurological development (Menke et al., 2018). For example, if a child experiences significant trauma at the age of five it can cause the brain to remain at that developmental age, making expected occupations as an older child difficult to reach such as self-care tasks, formal education participation, and age-appropriate play (Menke et al., 2018). This negative impact of trauma on development can be mitigated if the child is placed in a stable environment with supportive, nurturing caregivers (Conn et al., 2018; Frederico, Long, McNamara, McPherson, \& Rose, 2017; Messer et al., 2018). Caregivers must be trained in the impact of trauma and be equipped with strategies and interventions to support the child's continued development (Sinclair et al, 2016). Currently, research supports the use of a multidimensional treatment foster care approach, which combines foster parent training with skilled intervention for foster youth from trained professionals; foster parents who receive this type of training are referred to as treatment foster parents (Sinclair et al., 2016). Well-trained treatment foster parents can help increase placement stability and decrease problem behaviors from foster youth, but limited numbers of treatment foster parents are available to accept placements (Benesh \& Cui, 2017). Treatment foster parents are equipped with adequate skills to enable a child to feel secure and begin the "catch up" of their neurological development to perform ageexpected occupations.

\section{Purpose Statement}


The aim of this capstone project is to assess the need to enhance current trauma education courses to support the abilities of foster parents to manage children's challenging behaviors to help meet the needs of foster children who have experienced trauma. Additionally, this proposed project will advocate for and support existing legislation in the state of California requiring foster parents to receive evidence-based trauma education as part of their training before a child is placed in their home.

\section{Rationale for Project}

Occupational therapy can provide a unique and distinct perspective to foster parent education. Current education for foster parents does not include a course on how trauma can influence childhood development or occupational engagement. Occupational therapists utilize a unique perspective to create an individualized plan to help individuals across the lifespan to fully participate in occupations they need to do, want to do, and are expected to do daily (American Occupational Therapy Association [AOTA], n.d.-a). Occupational therapists are trained in lifespan development, social-emotional regulation, and increasing a parent and child's ability to participate in co-occupations together (i.e., playing together, reading together, etc.). For children, these can include participation in formal education, age-appropriate play, and self-care tasks. Trauma can impact a child's ability to perform these occupations, which can cause foster parents to become frustrated and can lead to placement instability for foster youth (Johnson \& Pryce, 2013). Occupational therapists lend a holistic perspective and examine what parts of a task may be difficult for a child. They then determine whether to modify an activity or modify the environment to increase a child's independence with their age-expected occupations.

This project is influenced by Attachment Theory (Bowlby, 1969). Originally developed by John Bowlby, this theory proposes that infants must establish a secure connection with a 
primary caregiver in order to experience a typical sequence of development (Bowlby, 1969;

Fraley, 2018). A disruption in the development of a relationship with a secure caregiver can lead to a child demonstrating insecure attachment patterns, which can have implications well into adulthood if not properly addressed (Fraley, 2018). Youth in the foster system have likely experienced separation form their primary caregiver and are unable to make secure attachment connections with foster parents due to the limited amount of time spent with foster parents (Haight, Kagle, \& Black, 2003). This proposed project draws on Attachment Theory to mitigate the effects of insecure attachment patterns and to provide foster parents with resources that promote placement stability, offering the child more opportunities to develop secure attachment patterns with a stable caregiver.

In addition to Attachment Theory, the proposed project also ties to the Occupation-Based Coaching model traditionally used in Early Intervention (EI) services. The coaching model is based on adult learning theories and enables parents to master skills that can be generalized to a variety of the child's contexts and environments (Simpson, 2015). Research supports the use of the coaching model for long-term use and helps facilitate continued participation in occupations during times of transition in the child's life (Simpson, 2015). The Occupation-Based Coaching principles will guide foster parents' education on how childhood trauma impacts occupational performance and how to master and retain the skills necessary to manage challenging behaviors in foster youth.

\section{Significance of the Project}

This project aims to improve the health of the foster youth/foster parent population through an intervention program based on evidence for foster parents. Research indicates that such an intervention for foster parents has multiple benefits to both the foster youth population as 
well as society at large. Foster youth benefit from such a program because they are likely to experience a decrease in placement changes, which is associated with many positive outcomes including increased self-esteem, increased academic success, decreased mental health symptoms, and increased coping skills (Bederian-Gardner et al., 2018; Liu et al., 2018; Price et al., 2009). Foster parents additionally may benefit from this program because of increased knowledge and skills they have to manage challenging behaviors (Price et al., 2009). This project aims to benefit society at large, most notably through a decreased financial burden for untreated childhood trauma and decreased costs for placement instability (Goldhaber-Fiebert et al., 2012).

Advocating for increased occupational participation for foster youth through this program expands the role of occupational therapy into this population. Educating foster parents on the impact of trauma may increase their awareness of how to increase participation in ageappropriate school, self-care, leisure, and play tasks (Dorsey et al., 2008; Price at al., 2009;). The proposed project provides an avenue for occupational therapy to provide services directly to foster parents and indirectly to foster youth, using occupational therapy in a new way to enhance the occupational performance of both foster youth and foster parents.

The proposed project additionally relates to policy development. Specifically, this project directly relates to implementing and developing a policy requiring trauma education for foster parents before they receive their license and before a child is placed in their home. Requiring foster parents to receive trauma education prior to placement may help increase placement stability, thereby decreasing the cost of placement instability on the taxpayers and community as well as mitigating the negative effects of placement instability on foster youth.

\section{Project Objectives}

The preliminary project objectives are as follows: 
1. Observe and analyze current training and education provided to foster parents

2. Interview foster parents to determine their satisfaction and perceived knowledge of childhood trauma

3. Examine current legislation related to foster parent training requirements

4. Identify opportunities to enhance current trauma curriculum and develop new trauma training integrating occupation-based knowledge

5. Education foster parents on the neurophysiological impact on experiencing trauma and how this impact related to a child's ability to perform age-expected occupations.

\section{Definition of Terms}

For this capstone project, trauma refers to both suspected trauma and actionable trauma. Trauma includes the most common types of trauma experienced by children in the foster care system including, but not limited to, neglect, family violence, traumatic grief/separation, physical abuse, emotional abuse, sexual abuse, and witness to criminal activity (Griffin et al., 2011). Suspected trauma is an event defined as not having sufficient evidence to conclude or suspect that the child experienced a traumatic event (U.S. Department of Health and Human Services [USDHHS], 2017). Additionally, an actionable trauma is an event with sufficient substantiating evidence to conclude that the child did experience a traumatic event (USDHSS, 2016).

Foster care (also called out-of-home care) is a temporary service provided to children who cannot reside with their biological families. Different types of placement settings include group homes, residential care facilities, emergency shelters, relatives, or unrelated foster parents (Children's Bureau, n.d.). Foster youth are children living temporarily in out-of-home care because their birth parents are unable to provide adequate care (Children's Bureau, n.d.). 
Occupational performance is the interaction between the person, their environment, and the occupation they are performing (Law, 1992). These three factors interact to impact a person's ability to perform an occupation to his or her level of satisfaction. Occupational engagement is the individual's level of participation in activities he or she finds personally meaningful.

\section{Assumptions}

This capstone project assumes that current trauma education for foster parents can be improved through an occupation-based enhancement. Additionally, this project assumes that foster parents are do not receive education on how trauma can impact a child's occupational performance and occupational engagement, which leads to placement instability as evidenced in Dorsey et al. (2008), Beyerlin \& Bloch (2014), and Hebert \& Kulkin (2018).

\section{Limitations}

The largest limitation in the proposed project is the temporary nature of foster care. Recent data indicates that children spend an average of 14.3 months in foster care (Child Welfare Information Gateway [CWIG], 2019), which does not allow significant time for foster parents to integrate the knowledge learned in occupation-based education. Participants in the project will be from one community foster care agency in San Diego, so the sample size will be limited to willing participants from one agency. Another limitation of this project is the varying range of ages of children in foster care. The median age of children in foster care is 7.7 years old, with children in foster care ranging from infancy to ages 18-years and up (CWIG, 2019). This wide variety of ages does not allow the project to direct the education to one specific age group.

\section{Delimitations}

This project includes some delimitations. First, based on the varying ages of children and the different types of trauma, the project will develop education for a large population of foster 
children with varying needs. This may impact the information included in the education for foster parents. Additionally, this project chooses to assess how trauma is a barrier for occupational performance in foster youth as opposed to youth not in the foster care system based on research showing that up to $95 \%$ of children in the foster care system experience trauma (Beyerlein \& Bloch, 2014; Griffin et al., 2011). Another delimitation is that the project focuses on an education program for foster parents as opposed to educating foster youth, which is supported by research indicating that foster parents want more education in managing challenging behaviors and helping children adjust to the home to improve placement stability for foster youth (Barnett et al., 2018; Hebert \& Kulkin, 2018). Finally, the project utilizes an occupational therapy perspective to develop education for foster parents and therefore will be more focused on how trauma can impact occupational performance and engagement. As previously stated, occupational therapists are trained in a wide variety of areas (e.g., lifespan development and social-emotional regulation) and can apply these skills to increase interaction between foster parents and foster children. Occupational therapists also can use these skills to facilitate increased engagement in meaningful co-occupations for both the foster parent and the foster child.

\section{Chapter II. Literature Review}

\section{Impact of Trauma and Placement Instability}

Current research demonstrates that upwards of $75 \%$ of children in the foster care system experience trauma, which causes them to enter the foster care system (Beyerlein \& Bloch, 2014; Griffin et al., 2011). Trauma may cause a child to experience difficulty forming secure attachments with caregivers, which can have negative effects on self-esteem in adulthood and can also affect a child's ability to have meaningful relationships with trusted adults (Liu et al., 
2018). An additional study concluded that foster youth often experience developmental difficulties in the physical, psychological, emotional, social, and intellectual domains (Fratto, 2016). Children may also demonstrate challenging behaviors (e.g., explosive behavioral outbursts and bed wetting) due to trauma (Hebert \& Kulkin, 2018). A randomized controlled trial found that children who experienced trauma had significant anatomical differences in their neurological systems and increased externalizing behaviors in stressful situations (Kuhlman, Geiss, Vargas, \& Lopez-Duran, 2018). Another study found that children at different ages will experience the same traumatic event differently and their brains will continue to develop abnormally if trauma is experienced in a critical period of development (Perry, 2009). Research shows the combination of developmental difficulties and challenging behaviors can lead to placement instability; foster parents feel unprepared to manage the challenging behaviors and feel that they cannot keep the child in their home (Frederico et al., 2017; Koh, Rolock, Cross, \& Eblen-Manning, 2014; Lee et al., 2017). Mnisi and Botha (2016) identified factors that foster youth feel contributed to placement breakdown including emotional and physical abuse by foster parents and disruptive behaviors of foster youth (e.g., substance abuse, inappropriate sexual behaviors). One study found that children in foster care report negative views on placement instability; they report feeling like a new placement disrupts their participation in school, forces them to make new friends, and challenges them to blend into a new family (Johnson, Yoken, \& Voss, 1995).

\section{Current Programs for Foster Parent Education}

Currently, in the state of California, foster parents are not required to take a course on trauma and its impact on a child's development to receive their foster care license (Dorsey et al., 2008). Many studies support the use of an evidence-based education program for foster parents 
to help mitigate the effects of trauma (Benesh \& Cui, 2017; Beyerlein \& Bloch, 2014; Conn et al., 2018; Messer et al., 2018). There are two primary evidence-based programs states can choose to educate foster parents: Keep Foster and Kin Parents Supported and Trained (KEEP) and the Child Adult Relationship Enhancement (CARE) program. Studies implementing the KEEP program have found that utilizing this program was more likely to result in a positive placement change for the child (i.e., reunification with biological parents) and decreases the risk of the child experiencing multiple placements (Benesh \& Cui, 2017; Greeno et al., 2015; Rivera \& Sullivan, 2015; Price et al., 2009). An additional model supported by research is the CARE program. One study implemented the CARE program with foster parents and found that those who participated in this program showed significant improvements in parenting behavior and reported fewer anxiety symptoms in their children (Messer et al., 2018). The CARE program has been shown to increase positive parenting attitudes and decrease the number of child behavior problems (Gurwich et al., 2016; Messer et al., 2018; Schilling et al., 2017). Though these programs are shown to be beneficial, they are voluntary programs and most foster parents do not experience these educational training programs.

\section{Foster Parent Needs}

Research indicates that foster parents want more education in managing challenging behaviors and helping children adjust to the home to improve placement stability for foster youth (Barnett et al., 2018; Hebert \& Kulkin, 2018). Foster parents have additional needs aside from increased behavioral education and training including respite services, education on psychological disorders, and training on legal procedures (Hebert \& Kulkin, 2018; Randle, Ernst, Leisch, \& Dolnicar, 2017). A systematic review of thirteen articles concluded that foster parents would like more education on parenting children with special needs, additional support after 
placement, understanding and responding to children's mental health difficulties, and a manual/handbook with different agencies and resources to help foster parents after placement (Barnett et al., 2019; Kaasbøll, Lassemo, Paulsen, Melby, \& Osborg, 2019). Additional research found that foster parents have difficulty allocating time for self-care (engaging in behaviors to sustain health and prevent burnout) as they often report feeling stressed about their foster care situation (Miller, Green, \& Lambros, 2019). This study also found that foster parents often need more than one type of self-care as compared to non-foster parents due to the high level of financial, relational, and social stressors associated with foster care (Miller et al., 2019). Foster parents need increased time for self-care activities (e.g., exercise, meditation, and journaling) and increased respite care services to allow them adequate time for self-care (Miller et al., 2019).

\section{Chapter III. Methods}

\section{Project Purpose}

A needs assessment was conducted at Straight from the Heart (SFTH) in San Marcos, California to determine the need for an occupation-based trauma education course in the San Diego County foster care system. During the process of conducting the needs assessment through observation of and participation in current SFTH courses, the doctoral student determined that this need was being met by classes already offered at SFTH. During the observation stage of the capstone project, it was determined that the format and structure of the current classes, specifically the pre-licensure classes, could be enhanced by utilizing specific group techniques and strategies offered by occupational therapists. Specifically, the group strategies could be utilized to incorporate additional activities to make the classes more encompassing of different learning styles, as the current format primarily was suited to those who learn well in a traditional classroom setting. Classes were limited in the kinds of activities catered to different learning 
styles. The purpose of the project changed to meet the needs of SFTH, and their current classes offered. Specifically, the doctoral student selected to focus on the Trauma Informed Pre-Service (TIPS) classes, which encompass the mandated twelve-hour training required in the county of San Diego to obtain a foster care license. These classes were selected because all foster parents are required to take these classes in San Diego County, so enhancing this specific curriculum will reach the largest number of potential foster parents.

The doctoral student utilized a specific set of interview questions to gather data from foster parents on their experiences with the pre-licensure classes and their preferred style of learning. Interview questions also aimed to gather information on the type of learning style that foster parents identified as. For the purposes of this project, four primary learning styles were included (visual, auditory, reading/writing, and kinesthetic) with a fifth option of "mixed" learning style where participants identified with a combination of two or more learning styles. These learning styles were used based on research indicating these are the most common types of learning styles in adults (Kamisli \& Özonur, 2019). See Appendix A for a list of interview questions used during verbal interviews with foster parents. All interviews were conducted over the phone and recorded for later reference.

\section{Participants}

Participants for the project were foster parents recruited from SFTH. In total, seventeen foster parents participated in these interviews. Foster parents varied in years of service as foster parents, number of children they fostered, and learning styles. Participants included twelve females and five males. Experience as a foster parent ranged from three to fifteen years with an average of 7.8 years of experience. Participants cared for an average of twelve foster children with individual numbers ranging from six to thirty foster children in their homes. The doctoral 
student recruited participants from a variety of methods including personal contacts, recruitment presentations at foster parent support groups, emails to the SFTH mailing list, flyers posted in the SFTH thrift store and offices, and word of mouth from other interview participants. The majority of participants were recruited via word of mouth from other interview participants who provided the doctoral student's contact information to them.

\section{Materials}

The needs assessment consisted of a specific set of interview questions for semistructured verbal interviews with foster parents developed in conjunction with input from SFTH staff, current foster parents, and the capstone project mentor. These questions aimed to gather information on the interview participants' preferred learning styles and their experiences with the pre-licensure courses. See Appendix A for a specific list of interview questions utilized during interviews with foster parents.

\section{Timeline}

The first four weeks of the capstone project included a thorough literature review of the topic and developing a preliminary draft of questions for interviews with foster parents. Beginning in week five of the project, the doctoral student observed foster parent classes (including the TIPS classes) and support groups. While observing these classes, the doctoral student determined that the appropriate trauma education was already offered at SFTH, so the student meet with faculty advisors and the project mentor to determine other areas of need at SFTH. The student also met with instructors and social workers to go over the required elements of the curriculum and identify areas in which the curriculum could be enhanced to facilitate better retention and a deeper understanding of the information provided during the classes. Observation of classes concluded in the thirteenth week of the capstone project and the 
interviews with foster parents and SFTH staff subsequently began in the thirteenth week of the capstone project to develop and enhance curriculum for foster parents. The curriculum development and enhancement became virtual with the Coronavirus Disease (COVID-19) pandemic with state government policies causing SFTH to close for the remainder of the capstone experience project. The last four weeks of the capstone experience were spent working with SFTH staff to develop online curriculum and teacher training for use at SFTH. In addition, the doctoral student provided SFTH with an informal presentation and a handout with suggestions to enhance the TIPS curriculum based on interviews with foster parents and research on different learning theories. See Appendix B for the handout provided to SFTH.

\section{Analysis \& Envisioned Next Steps}

The capstone project completed throughout analysis of all verbal interviews with foster parents for recurring themes. The results from identifying themes assisted in the program development portion of the capstone project to ensure that the education program is salient to both participating families and staff members at SFTH. Staff members provided input and collaborated with the doctoral student to enhance the trauma education for foster parents. The staff members at SFTH completed a training on the proposed curriculum enhancements to help ensure that the program continues to function after completion of the capstone project. Ultimately, the long-term goal of this proposed capstone project is to consistently implement the enhanced trauma education with all foster parents in their initial foster care licensure training and in their licensure renewal education. A long-term goal for this project is to support legislation requiring the enhanced trauma education for all foster parents in the state of California.

\section{Chapter V. Results}

\section{Types of Learning Styles}


Several common themes emerged during the interviews with seventeen foster parents. Seventeen interviews with foster parents were conducted over the phone utilizing the questions outlined in Appendix A. These interviews were recorded and analyzed for common themes. The first significant finding is the breakdown of different learning styles amongst participants. The breakdown of preferred learning styles is displayed in Figure 1. Figure 1 displays the distribution of learning styles. The distribution of learning styles was not overwhelmed by one particular style, indicating a need for the TIPS curriculum to meet a wide variety of individual learning needs. Of those who selected a mixed learning style, the most common combination was kinesthetic and reading/writing (23\%) followed closely by auditory and reading/writing (18\%). The choices for preferred learning styles were described to foster parents as follows (Advancement Courses, 2019):

- Visual: processes information using charts and graphs, needs images to explain concepts \& ideas, prefers graphic elements over written words

- Auditory: learns best when information is spoken, prefers lectures \& discussions, processes information by talking through things

- $\quad$ Reading/Writing: prefers to receive written words, enjoys reading and writing assignments, processes information by writing notes

- Kinesthetic: learns best through tactile processes, prefers to create concrete personal experiences, processes information by recreating \& practicing 
- Mixed: a combination of two (2) or more of the above learning styles

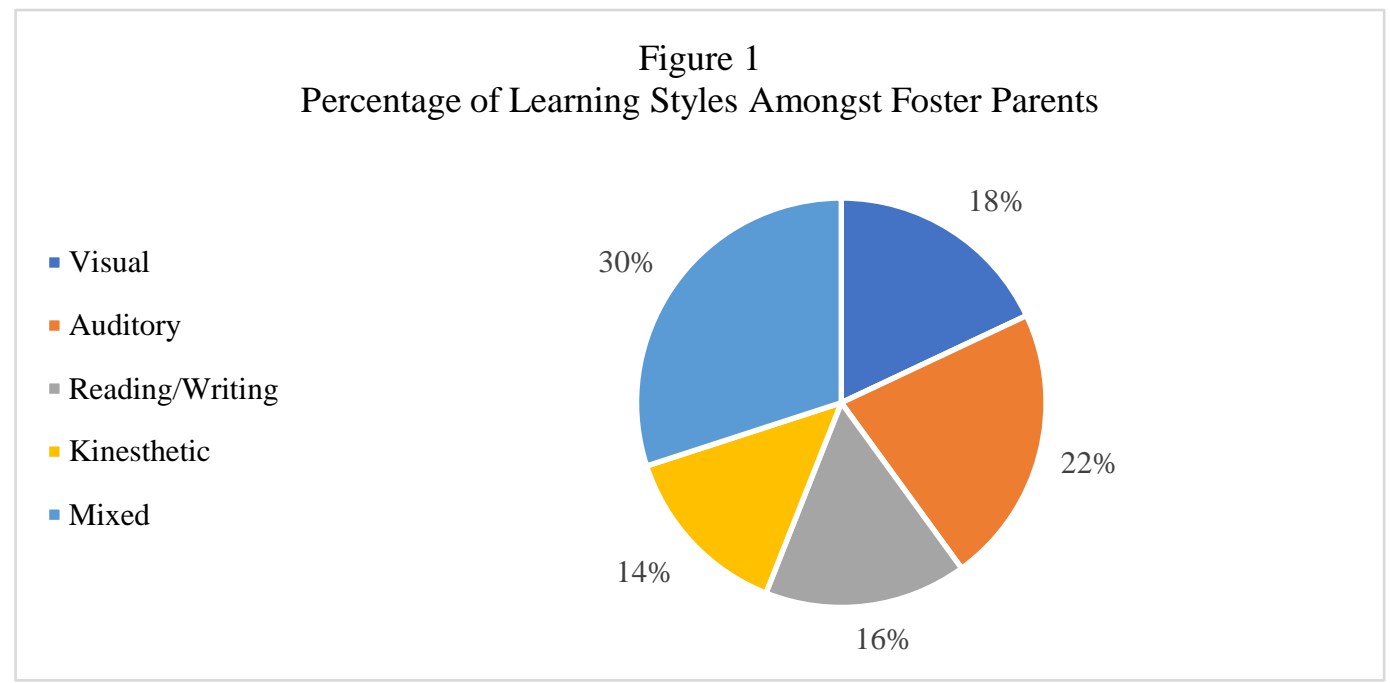

Additionally, when asked if they felt their pre-licensure training supported their preferred learning style, $88 \%$ of participants reported they did not feel their training supported their preferred learning style.

\section{Changes to the TIPS Curriculum}

Interestingly, $100 \%$ of participants stated they would alter the curriculum if they could to include activities that were more suited towards their preferred style of learning despite $12 \%$ feeling that the original curriculum supported their learning needs. Some suggestions for the TIPS curriculum included more hands-on learning activities, additional handouts to take home outlining the specifics of different foster care scenarios, and more open discussion on topics related to foster care. The most common suggestion for enhancing the TIPS curriculum mentioned by $74 \%$ of participants was including additional hands-on activities. In addition, $65 \%$ of participants noted that they would like more open discussions with experienced foster parents during TIPS classes on how to practically implement the tools and strategies learned in the TIPS classes with foster children. Specifically, participants stated they want more open discussion on the topics of how to keep track of paperwork and files, suggestions for how to manage the child's family visitation schedule, and legal terms used in foster care. 


\section{Strengths of Straight from the Heart TIPS Classes}

Several strengths of SFTH TIPS classes were identified through the semi-structured interviews with foster parents. The main strength interview participants consistently noted was the benefit of having both an experienced foster parents and a foster care social worker as instructors during the TIPS classes. One participant stated, "The most helpful part was hearing the experiences from foster parents who have already gone through a lot of this." Other participants echoed this sentiment with $74 \%$ of participants stating the benefit of the dual perspective in the TIPS classes. One interview participant said, "Both the social worker and the foster parent gave so many tips and tricks to navigating the foster system. I can't imagine the classes without that." The majority of participants $(65 \%)$ identified that the dual perspective was so helpful because it provided practical knowledge from the foster parent combined with the professional knowledge of the social worker.

Foster parents also identified the voluntary mentorship program at SFTH to be an additional strength to the TIPS curriculum. At the conclusion of the TIPS classes, the class instructors pair up the newly licensed foster parents with an experienced foster parent who serves as a mentor. Foster parents can choose to sign up for a mentor if they are interested in doing so. All foster parents are highly encouraged to sign up for mentorship. Currently, each mentor works with about four newly licensed foster parents. An overwhelming majority (94\%) of participants identified that the mentorship program was critical to their success as foster parents. When asked how they felt the mentorship program was beneficial, one participant stated the following:

I don't think I could have gotten through the first year of foster care without my mentor. There is so much that you learn about in class and it kind of overwhelms you. My mentor helped me through the very muddy waters of foster care and helped me to be the best 
foster parent I could be to the children who come into my home. Everything in foster care can change so quickly and I love having someone who can support me through it. You can't really support someone as a foster parent unless you're also a foster parent. There's a lot that you can only understand if you're in it yourself. Even after doing this for ten years I still need my mentor!

When asked if they were pleased with their mentor, $94 \%$ of participants responded that they were pleased with their mentor and the relationship they have with their mentor. Of the interview participants, $17 \%$ also serve as mentors to newly licensed foster parents. They feel this is beneficial to them, too. A current mentor stated that serving as a mentor "keeps me on my toes. I have to be up to date on all of the policies and procedures. It makes me a better foster parent." Another mentor said, "my mentor in the early years was my lifeline. I am so happy knowing that I can be that lifeline for someone else."

\section{Chapter VI. Analysis}

\section{Analysis}

The results from the qualitative verbal interviews suggest that there are several ways to enhance the TIPS curriculum in addition to highlighting the current strengths of the TIPS classes. Interview results indicate the variety of learning styles amongst foster parents (see Figure 1). This wide array of learning styles indicates a need to adapt the curriculum to best meet the needs of all foster parents. Research demonstrates that the most common types of learning styles among adults include visual, reading/writing, auditory, kinesthetic, and mixed learning styles (Advancement Courses, 2019), which were the choices offered to foster parents during the verbal interviews. Interview participants noted that they want more hands-on experiences in class to help them understand the difficult concepts. The combination of the breakdown of learning styles 
and the comments from foster parents saying they want to add activities to the classes suggest that the TIPS curriculum should be enhanced to support foster parents in this training. The doctoral student, in collaboration with TIPS instructors, utilized occupational therapy group design skills to combine suggestions from foster parents with the strengths of current TIPS programming to enhance the TIPS curriculum.

Occupational therapy groups are unique in that they focus solely on activity and changing areas of performance skills and patterns (Cara \& MacRae, 2012). Through interviews and observations, it was determined that the TIPS classes function closest to a mature group, meaning they can work together to solve conflicts and have a high cognitive ability (Cole, 2012). This indicates that the TIPS courses would benefit from the TIPS instructors utilizing an advisory leadership approach, which includes the instructors working alongside the participants to enable group members to make decisions for the group and to allow group members to function at their highest capacity (Cole, 2012).

The specific suggestions to enhance TIPS curriculum can be found in Appendix B and include two different hands-on activities to implement during the TIPS classes. Including handson learning activities for adult learners is consistent with literature supporting the use of these activities to increase retention of knowledge (Davis, 2013; Thorsteinsson \& Page, 2018; Wells, VanLeeuween, Seevers, \& White, 2019). TIPS instructors participated in a two-hour training on how to implement the activities in classes before the conclusion of the capstone project, which helped ensure the long-term sustainability of the capstone project. The TIPS instructors were receptive to all suggestions and engaged in an open discussion with the doctoral student about the benefits of implanting these suggestions as well as any hesitations they had about changing the curriculum. Suggestions made to enhance the TIPS curriculum were based on the data 
collected during verbal interviews with current foster parents, social workers, and current TIPS instructors.

The main premise of the suggestions was to include more hands-on learning opportunities for class participants, especially activities to help class participants better understand abstract concepts including how trauma can impact a child's overall development. Much consideration was taken to include activities that utilized supplies SFTH already has to help ease the integration of the activities into the curriculum. One example of an activity included in the suggested curriculum enhancement in having class participants create what they think a child who experienced trauma looks like. The class participants can use different media to create their child including cutouts from magazines, drawings, or words. The TIPS instructors then hold an open discussion about what each participant created and how they might see some signs and symptoms of trauma manifest in their child. Overall, the staff were excited about implementing the changes to create the biggest impact for the foster parents of San Diego county.

\section{Chapter VI. Summary, Discussions, and Conclusions}

\section{Summary}

Throughout the capstone experience, the doctoral student conducted a thorough literature review, observed current classes offered to foster parents, and interviewed foster parents to identify ways to enhance the TIPS curriculum. These included the addition of hands-on activities for the TIPS classes and more open discussion with foster parents. The purpose of these suggestions is to help foster parents achieve a deeper understanding of the knowledge and maintain a higher retention of the knowledge when they begin caring for foster children in their home. These recommendations were made specifically for the pre-licensure classes for foster parents in San Diego County. The majority of participants identified wanting more hands-on 
activities to help them better understand the materials and more abstract concepts, like how trauma can impact a child.

The project also found several strengths of the current TIPS curriculum offered at SFTH. Interviews demonstrated that foster parents enjoy the mentorship program offered at SFTH with $94 \%$ of participants stating they found the mentorship program critical to their success as foster parents. Some of the interview participants serve as mentors to others now that they are more experienced. An additional strength highlighted throughout the interviews is the incorporation of both an experienced foster parent and a social worker as the TIPS instructors. Interview participants consistently noted how valuable they felt this dual perspective is to their learning. They noted that the knowledge of the foster parents and the knowledge of the social workers combined gave them a realistic idea of what to expect when they began taking foster children into their home.

The project identified the variation of learning styles amongst interviewees and provided SFTH with ways to best support the needs of all class participants. The variety of learning styles amongst interview participants indicates a need to alter the curriculum to support a greater number of foster parents in the pre-licensure classes. The current TIPS curriculum caters to primarily those who identify with a reading/writing style of learning, which is only $16 \%$ of participants, leaving $84 \%$ of participants without activities for their preferred style of learning. The doctoral student created and presented the TIPS curriculum enhancement suggestions with TIPS instructors to meet the needs of a greater array of learning styles in the TIPS classes.

Current TIPS curriculum and programming has many strengths that interview participants found beneficial to their experiences as foster parents. These strengths included the dual perspective of instructors during the TIPS classes and the mentorship program. Suggestions for 
enhancing the TIPS curriculum include more opportunities for the instructors to share about topics the foster parents find the most useful. Additionally, the suggestions include a stronger promotion of the mentorship program at SFTH to encourage all TIPS class members to participate.

\section{Discussion}

Though the project focus shifted once the needs assessment began, the project still identified useful tools and suggestions for ways to enhance the TIPS curriculum. The initial proposed project included utilizing the Scale for Assessment of Family Enjoyment within Routines (SAFER) (Appendix C), the Parental Stress Scale (Appendix D), and qualitative verbal interviews with foster parents to determine the need for an occupation-based trauma education course for foster parents. Through observation of current classes and discussions with SFTH instructors and social workers, it was determined that there was not a need for a new occupationbased trauma education course. During the needs assessment, a need was identified relating to the structure of classes to better support more class participants to retain the knowledge and deepen their understanding of the material. This need was presented to the SFTH instructors and social workers, who agreed that this was indeed a need at SFTH. The project then shifted focus to develop suggestions to support a greater variety of learning styles within the TIPS courses and curriculum.

The capstone project has many implications primarily for those who serve foster parents. The findings of the capstone project indicate a greater need to adapt foster parent education classes to support a greater variety of learning styles. Occupational therapists can work with community agencies and utilize specific group strategies to help enhance their pre-licensure training curriculum. Additionally, social workers and marriage and family therapists who also 
teach foster parent education courses can implement these strategies to increase the retention of knowledge and facilitate a deeper understanding of the knowledge amongst foster parents. Though the project did generate interesting findings, these findings are not without limitations. The first of these is the small sample size. There were only seventeen interview participants, making it hard to generalize the findings to much larger populations. Also, the project only included foster parents from San Diego County who received their pre-licensure training at SFTH. This is a specific organization with a specific population, so the findings may not be generalizable to all populations or organizations.

This capstone experience generated many implications that can help enhance foster parent education in San Diego County. Foster parents will hopefully have an easier transition applying the strategies at home when they begin caring for foster children by enhancing the curriculum to increase retention of the knowledge and facilitate a deeper understanding of the materials. If foster parents are readily able to apply the strategies from TIPS when they receive a child, they will ideally feel more confident in having these children in their homes. This in turn will decrease the placement instability that foster youth who have a history of trauma often experience as the foster parents will have a firm base of knowledge for how to help the child. Ultimately, the benefit of this project is the universal implementation of the enhanced curriculum suggestions, which will decrease placement stability for foster youth and increase confidence of foster parents to continue serving the youth in need.

\section{Conclusions}

This capstone project sought out to identify education gaps in education for foster parents. The project identified an area of concern in the way the material was presented to foster parents. In collaboration with foster parents and foster parent educators, the doctoral student 
created suggestions to enhance the TIPS curriculum to better meet the educational needs of more foster parents. These suggestions were well received by TIPS instructors and will be implemented in the TIPS classes beginning in June of 2020.

This project added to the body of knowledge for those serving foster parents including social workers, licensed marriage and family therapists, and occupational therapists. The findings from the capstone project help meet a need for foster parent education in San Diego County. Suggestions for future research in the area of foster parent education include virtual classes for foster parent education, the application of a mentorship program for foster care in counties where there currently is not one, and researching the difference between foster parents who receive the traditional TIPS classes and those who receive the enhanced TIPS classes. 


\section{References}

Advancement Courses. (2019). 4 Types of Learners in Education: Advancement Courses. Retrieved from https://blog.advancementcourses.com/articles/4-types-of-learners-ineducation/

American Occupational Therapy Association [AOTA] (n.d.-a). OT in schools. Retrieved from https://www.aota.org/about-occupational-therapy/patietnsclients/childrenandyouth/schools.schools.aspx

American Occupational Therapy Association [AOTA] (n.d.-b). What is occupational therapy? Retrieved from https://www.aota.org/Conference-Events/OTMonth/what-is-OT.aspx

Barnett, R., Jankowski, M., Butcher, R., Meister, C., Parton, R., \& Drake, R. (2018). Foster and adoptive parent perspectives on needs and services: A mixed methods study. Journal of Behavioral Health Services and Research, 45(1), 74-89. doi: 10.1007/s11414-017-9569-4

Bederian-Gardner, D., Hobbs, S. D., Ogle, C. M., Goodman, G. S., Cordón, I. M., Bakanosky, S., ... Chong, J. Y. (2018). Instability in the lives of foster and nonfoster youth: Mental health impediments and attachment insecurities. Children and Youth Services Review, 84, 159-167. https://doi.org/10.1016/j.childyouth.2017.10.019

Benesh, A. S., \& Cui, M. (2017). Foster parent training programmes for foster youth: A content review. Child \& Family Social Work, 22(1), 548-559. https://doi.org/10.1111/cfs.12265

Beyerlein, B. A., \& Bloch, E. (2014). Need for trauma-informed care within the foster care system: A policy issue. Child Welfare, 93(3), 7-21. Retrieved from http://search.ebscohost.com/login.aspx?direct=true\&db=heh\&AN=110870975\&site=edslive

Bowlby J. (1969). Attachment. Attachment and loss: Vol. 1. Loss. New York: Basic Books. 
Cara, E., \& MacRae, A. (2012). Psychosocial occupational therapy: An evolving practice ( $3^{\text {rd }}$ ed.). Cifton Park, NY. Delmar.

Child Welfare Information Gateway. (2019). Foster care 2017. (Rep). Retrieved from https://www.childwelfare.gov/pubs/factsheets/foster/

Children's Bureau. (n.d.). Foster care. Retrieved from https://www.childwelfare.gov/topics/outofhome/foster-care/

Cole, M. (2012). Group dynamics in occupational therapy: The theorietical basis and practice applicatioOn of group intervention $4^{\text {th }}$ ed.). Thorofare, NJ. Slack.

Conn, A., Szilagyi, M., Alpert-Gillis, L., Webster-Stratton, C., Manly, J., Goldstein, N., \& Jee., S. (2018). Pilot randomized controlled trial of foster parent training: A mixed-methods evaluation of parent and child outcomes. Children and Youth Services Review, 89, 188197. doi:10.1016/j.childyouth.2018.04.035

Davis, H.S. (2013). Discussion as a bridge: Strategies that engage adolescent and adult learning styles in the postsecondary classroom. Journal of the Scholarship of Teaching and Learning, 13(1), 68-76. https://eric.ed.gov/?id=EJ1011682

Dorsey, S., Farmer, E. M. Z., Barth, R. P., Greene, K. M., Reid, J., \& Landsverk, J. (2008). Current status and evidence base of training for foster and treatment foster parents. Children and Youth Services Review, 30(12), 1403-1416. https://doi.org/10.1016/j.childyouth.2008.04.008

Fratto, C. M. (2016). Trauma-informed care for youth in foster care. Archives of Psychiatric Nursing, 30(3), 439-446. https://doi.org/10.1016/j.apnu.2016.01.007 
Frederico, M., Long, M., McNamara, P., McPherson, L., \& Rose, R. (2017). Improving outcomes for children in out-of-home care: The role of therapeutic foster care Child \& Family Social Work, 22(2), 1064-1074. doi: 10.1111/cfs.12326

Goldhaber-Fiebert, J.D., Bailey, S. L., Hurlburt, M.S., Zhang, J., Snowden, L.R., Wulczyn, F., ... Horowitz, S.M. (2012). Evaluating child welfare policies with decision-analytic simulation models. Administration and Policy in Mental Health and Mental Health Services Research; New York, 39(6), 466-477. http://dx.doi.org.prxusa.lirn.net/10.1007/s10488-011-0370-z

Greeno, E., Uretsky, C., Lee, B., Moore, J., Barth, R, \& Shaw, T. (2015). Replication of the KEEP foster and kinship parent training program for youth with externalizing behaviors. Children and Youth Services Reivew, 61, 75-82. http://dx.doi.org/10.1016/j.childyouth.2015.12.003

Griffin, G., McClelland, G., Holzberg, M., Stolbach, B., Maj, N., \& Kisiel, C. (2011). Addressing the impact of trauma before diagnosing mental illness in child welfare. Child Welfare, 90(6), 69-89. Retrieved from http://prxusa.lirn.net/login?url=http://search.ebscohost.com/login.aspx?direct=true \&db=heh\&AN= $74247646 \&$ site=eds-live

Gurwich, R., Messer, E., Masse, J., Olafson, E., Boat, B., \& Putnam, F. (2016). Child-Adult Relationship Enhancement (CARE): An evidence-informed program for children with a history of trauma or other behavioral challenges. Child Abuse and Neglect, 53, 138-145. doi: 10.1016/j.chiabu.2015.10.016

Haight, W. L., Kagle, J. D., \& Black, J. E. (2003). Understanding and supporting parent-child relationships during foster care visits: Attachment Theory and research. Social Work, 
48(2), 195-207. Retrieved from http://prx-

usa.lirn.net/login?url=http://search.ebscohost.com/login.aspx?direct=true \&db=heh\&AN= $9586343 \&$ site $=$ eds-live

Hebert, C. G., \& Kulkin, H. (2018). An investigation of foster parent training needs. Child \& Family Social Work, 23(2), 256-263. https://doi.org/10.1111/cfs.12413

Johnson, P., Yoken, C., \& Voss, R. (1995). Family foster care placement: The child's perspective. Child Welfare, 74(5), 959-974. Retrieved from http://prxusa.lirn.net/login?url=http://search.ebscohost.com/login.aspx?direct=true \&db=heh\&AN= $24227363 \&$ site $=$ eds-live

Johnson, S. B., \& Pryce, J. M. (2013). Therapeutic mentoring: Reducing the impact of trauma for foster youth. Child Welfare, 92(3), 9-25. Retrieved from http://prxusa.lirn.net/login?url=http://search.ebscohost.com/login.aspx?direct=true \&db=heh\&AN= 92045408\& site=eds-live

Kaasbøll, J., Lassemo, E., Paulsen, V., Melby, L., \& Osborg, S. (2018). Age-specific risk factors associated with placement instability among foster children. Child Abuse and Neglect, 84, 157-169. doi: 10.1016/j.chiabu.2018.07.024

Kamisli, H., \& Özonur, M. (2019). Students' learning styles in vocational education. International Journal of Curriculum and Instruction, 11(1), 209-220. https://eric.ed.gov/?id=EJ1217911

Koh, E., Rolock, N., Cross, T., \& Eblen-Manning, J. (214). What explains instability in foster care? Comparison of a matched sample of children with stable and unstable placements. Children and Youth Services Review, 37, 36-45. doi: 10.1016/j.childyouth.2013.12.007 
Kuhlman, K., Geiss, E., Vargas, I., \& Lopez-Duran, N. (2018). HPA-axis activation as a key moderator of childhood trauma exposure and adolescent mental health. Journal of Abnormal Child Psychology, 46(1), 149-157. doi: 10.1007/s10802-017-0282-9

Law, M. (1992). Planning for children with physical disabilities: Identifying and changing disabling environments through participatory research. (Doctoral dissertation, University of Waterloo, Waterloo, Canada). Retrieved from ProQuest Dissertations \& Theses Global (UMI No 304050767)

Lee, E., Choi, M., Lee, Y.., \& Kramer, C. 2017. Placement stability of children in kinship care: Age, poverty, and involvement in the child welfare system. Child Welfare, 95(3), 87-110. Retrieved from http://prxusa.lirn.net/login?url=http://search.ebscohost.com/login.aspx?direct=true $\& \mathrm{db}=$ heh $\& A N=$ $126410665 \&$ site $=$ eds-live

Liu, C., Chen, X., Song, P., Lu, A., Wang, L., Zhang, X. ... Zheng, D. (2018). Relationship between childhood emotional abuse and self-esteem: A dual mediation model of attachment. Social Behavior \& Personality: An International Journal, 46(5), 793-800. Retrieved from http://prxusa.lirn.net/login?url=http://search.ebscohost.com/login.aspx?direct=true $\& d b=s 3 h \& A N=$ $129468917 \&$ site $=$ eds-live

Menke, A., Lehrieder, D., Fietz, J., Leistner, C., Wurst, C., Stonawski, S., ... Domschke, K. (2018). Childhood trauma dependent anxious depression sensitizes HPA axis function. Psychoneuroendocrinology, 98, 22-29. https://doi.org/10.1016/j.psyneuen.2018.07.025

Messer, E. P., Greiner, M. V., Beal, S. J., Eismann, E. A., Cassedy, A., Gurwitch, R. H., ... Eiler-Sims, P. (2018). Child adult relationship enhancement (CARE): A brief, skills- 
building training for foster caregivers to increase positive parenting practices. Children and Youth Services Review, 90, 74-82. https://doi.org/10.1016/j.childyouth.2018.05.017

Miller, A., Green, T., \& Lambros, K. (2019). Foster parent self-care: A conceptual model. Children and Youth Services Review, 99, 107-114. doi: 10.1016/j.childyouth.2019.01.014

Mnisi, R. \& Botha, P. (2016). Factors contributing to the breakdown of foster care placements: The perspective of foster parents and adolescents. Social Work, 52(5), 227-244. doi: $10.15270 / 52-2-502$

Perry, B. D. (2009). Examining child maltreatment through a neurodevelopmental lens: Clinical applications of the neurosequential model of therapeutics. Journal of Loss and Trauma, 14(4), 240-255. Retrieved from http://prxusa.lirn.net/login?url=http://search.ebscohost.com/login.aspx?direct=true $\& d b=$ eric $\& A N=$ EJ857294\&site=eds-live

Price, J. M., Chamberlain, P., Landsverk, J., \& Reid, J. (2009). KEEP foster-parent training intervention: Model description and effectiveness. Child \& Family Social Work, 14(2), 233-242. https://doi.org/10.1111/j.1365-2206.2009.00627.x

Randle, M., Ernst, D., Leisch, F., \& Dolnicar, S. (2018). What makes foster carers think about quitting? Recommendations for improved retention of foster carers. Child and Family Social Work, 22(3), 1175-1186. http://dx.doi.org/10.1111/cfs.12334

Rivera, M. \& Sullivan, R. (2015). Rethinking child welfare to keep families safe and together: Effective housing-based supports to reduce child trauma, maltreatment recidivism, and re-entry to foster care. Child Welfare, 94(4), 185-204. Retrieved from http://prxusa.lirn.net/login?url=http://search.ebscohost.com/login.aspx $?$ direct=true $\& d b=c c m \& A N$ $=110870819 \&$ site $=$ eds-live 
Schilling, S., French, B., Berkowitz, S., Doughtery, S., Scribano, P., \& Wood, J. (2017). ChildAdult Relationship Enhancement in primary care (PriCARE): A randomized trial of parent training for child behavior problems. Academic Pediatrics, 17(1), 53-60. doi: 0.1016/j.acap.2016.06.009

Sinclair, I., Parry, E., Biehal, N., Fresen, J., Kay, C., Scott, S., \& Green, J. (2016). Multidimensional Treatment Foster Care in England: Differential effects by level of initial antisocial behaviour. European Child \& Adolescent Psychiatry, 25(8), 843-852. https://doi.org/10.1007/s00787-015-0799-9

Thorsteinsson, G., \& Page, T. (2018). The standing of hands-on learning in education. Journal on Educational Psychology, 11(3), 1-11. https://eric.ed.gov/?id=EJ1173817

U.S. Department of Health \& Human Services (2017). The AFCARS Report (Rep.). Retrieved from https://www.acf.hhs.gov/cb/resource/afcars-report-25

U.S. Department of Health and Human Services. (2017, October 20). The AFCARS Report (Rep.). Retrieved from https://www.acf.hhs.gov/cb/resource/afcars-report-25

Wells, K., VanLeeeuwen, D., Seevers, B., \& White, L. (2019). Impact of traditional lecture and hands-on learning on students' knowledge gain in animal science courses. NACTA Journal, 63(2), 319-321. https://www.nactateachers.org/index.php/vol-63-2-apr-oct2019/2877-impact-of-traditional-lecture-and-hands-on-learning-on-students-knowledgegain-in-animal-science-courses 


\section{Appendix A}

Interview Questions for Semi-Structured Verbal Interviews with Foster Parents

1. How long have you been a foster parent? What got you interested in doing foster care?

2. Approximately how many foster children have you cared from in your home?

3. What were your initial training classes like? How many classes were there? How many hours of training were required?

4. What is your preferred learning style from the following choices?
a. Visual
b. Auditory
c. Reading and Writing
d. Kinesthetic
e. Mixed

5. Do you feel like your initial training classes supported your preferred learning style?

a. Were there a variety of activities that were more suited towards each different learning style or did they all seem to be more focused towards one style?

6. Is there anything you wish was different about the initial classes? Is there anything you wish you could add to the initial classes?

7. Do you feel that having more activities that fit in with your style of learning would have helped you retain the information better and apply it easier once you began fostering?

8. Do you participate in the mentorship program? If so, do you feel that it is helpful? Why or why not? 


\author{
Appendix B \\ Handout with Suggestions for TIPS Curriculum Enhancement
}

Types of Learning Styles ${ }^{1}$

1. Visual Learning

- Process information using charts and graphs

- Need images to explain concepts \& ideas

- Prefer graphic elements over words

2. Auditory Learning

- Learn best when information is spoken

- Prefer lectures \& discussions

- Process information by talking through things

3. Read/Write Learning

- Prefer to receive written words

- Enjoy reading and writing assignments

- Process information by writing notes

4. Kinesthetic Learning

- Learn best through tactile processes

- Prefer to create concrete personal experiences

- Process information by recreating \& practicing

\title{
Notes from Interviews with Foster Parents
}

1. Learning style breakdown is as follows:

- Visual: $18 \%$

- Auditory: $22 \%$

- Read/Write: $16 \%$

- Kinesthetic: $14 \%$

- Mixed: $30 \%$

2. Comments from foster parents on introductory pre-licensure classes:

- "The most helpful part was hearing the experiences from foster parents who have already gone through a lot of this."

- "I wish there was more interactive learning, like making things or getting up and moving"

- "Some of the things you learn about in class don't really resonate with you until you experience the situation yourself"

- "For me, the most beneficial part of these classes was the handouts and worksheets we got to take home. It's a really helpful reference."

3. Top three suggestions for changes to T.I.P.S. classes:

- More "hands-on" activities

- Additional handouts/flowcharts for different scenarios

- More open discussion in classes about experiences with the current foster parent

References:

1: Advancement Courses. (2019). 4 Types of Learners in Education: Advancement Courses. Retrieved from https://blog.advancementcourses.com/articles/4-types-of-learners-in-education/ 


\section{Suggestions for Enhancing T.I.P.S. Curriculum:}

1. Begin each session asking participants about their preferred learning style.

- Can be done informally with a show of hands or privately by using a post-it note for participants to write on and pass to the front

- If any new participants join after the first session, ask them their learning style before beginning class to incorporate their needs, too.

- Note: most participants will identify as a "mixed" learning style

2. Hands-On Activity Suggestions:

- Building a child who has experienced trauma

- Materials:

- Basic paper doll cut out shape

- Magazines

- Glue sticks

- Scissors

- Markers

- Instructions:

- Instruct participants to create how they think a child who has experienced trauma would look using the materials in front of them. Participants can create something more abstract or something more literal. Engage in an open discussion with the group having each participant share about their child and why they made their child look that specific way.

- Perform this activity in the first session of T.I.P.S. classes and again at the end to see how participants' perspectives on trauma changed.

- Making a Trauma Toolkit

- Materials:

- Print outs with outlines of a toolbox and tools

Make sure there are the same number of tools as there are strategies

in the curriculum

- Scissors

- Markers

- Instructions:

- When going over different strategies to help children who have experienced trauma, provide participants with the print outs, scissors, and markers.

- As you discuss each strategy, have the participants decide which tool they will make that strategy. Ask them to cut it out and label it with the specific strategy and add anything they feel will help them remember it more.

- It is okay if different participants select different tools for the same strategy!

3. Suggestions for Discussion Topics:

- Note: the following discussion topics are based on suggestions from interviews with foster parents.

- Fears/things that scare you about foster care (even though you really want to do it!).

- Legal terms we don't always understand

- How to keep track of paperwork/files

- Suggestions to manage all of the different kinds of visits (and how to keep track of them all) 
Appendix C

Scale for Assessment of Family Enjoyment within Routines

(SAFER)

\section{Scale for Assessment of Family Enjoyment within Routines}

(SAFER)

Stacy Scott \& R. A. McWilliam (2000, Revised 4/03)

Frank Porter Graham Child Development Center University of North Carolina At Chapel Hill

This routines-based interview is an assessment tool designed for professionals working with families to develop functional intervention plans. By gathering information from the family about home and community routines, professionals can identify the independence, engagement, and social competence of the child, and the concerns and priorities of the family. The goals and outcomes generated from this assessment are (a) functional (i.e., identify immediately useful skills the child needs to get throughout the day), and (b) transdisciplinary (i.e., do not have to be addressed by a professional of a specific discipline). The general questions included in this instrument are intended to guide professionals through the assessment process. Professionals are encouraged to develop their own questions to follow up with each family's unique experiences. Questions for community care (e.g., child care center) are included for those families whose children participate in caregiving environments outside of their home.

Directions: Ask appropriate questions under each routine, making notes of the family's responses to the right. After all routines have been discussed, the interviewer reviews the concerns that were mentioned for each routine with the family. The interview asks the family to rate the routine on the following scale. Be sure to record a number for each routine.

1

Not at all satisfied
2

Satisfied
4

5

The family chooses which concerns they would like to have addressed as outcomes or goals. Progress on outcomes or goals may be measured over time by asking the family to rate their satisfaction of routines addressed in interventions again. 


\section{Scale for Assessment of Family Enjoyment within Routines}

(SAFER)

\section{Waking up}

- Could you describe what wake up time is like?

- Who usually wakes up first?

- Where does your child sleep?

- How does your child let you know she is awake?

- Does she wan to be picked up right away? If so, is she happy when picked up?

- Or is she content by herself for a few minutes? What does she do?

- What is the rest of the family doing at this time?

- Is this a good time of day? If not, what would you like to be different?

Satisfied?

\section{Notes}

ferent? 


\section{Diapering/Dressing Home}

- What about dressing? How does that go?

Notes

- Who helps your child dress?

- Does he help with dressing? How? What can he do on his own?

- What is his mood like?

- What is communication like?

- Does your child wear diapers?

- Are there any problems with diapering?

- What does your child do while you are changing him?

- Does your child use the toilet? How independently?

- How does he let you know when he needs to use the toilet?

- How satisfied are you with this routine? Is there anything you would like to be different?

Satisfied? 


\section{Feeding/Meals}

\section{Home}

- What are feedings/mealtimes like?

- Does anyone help feed your child? Who?

- How often does she eat?

- How much can she do on her own?

- How involved is she with meals?

- Where does your child usually eat?

- What are other family members doing at this time?

- How does your child let you know what she wants or whether she is finished?

- Does she like mealtimes? How do you know?

- What would make mealtimes more enjoyable for you?

Satisfied?

\section{Community Care}

- What are mealtimes like for your child when under the care of others?

Satisfied? 


\section{Getting ready to go/Traveling}

\section{Home}

- How do things go when you are getting ready to go somewhere with your child?

- Who usually helps your child get ready?

- How much can he do on his own?

- How involved is he in the whole process of getting ready to go?

- What is communication like at this time?

- Does your child like outings? How do you know?

- Is this a stressful activity? What would make this time easier for you?

\section{Satisfied?}

\section{Community Care}

- What are drop off and pick up times like for your child? Do you or other caregivers have any concerns?

\section{Satisfied?}

\section{Hanging out/Watching TV}

- What does your family do when relaxing at home?

- How is your child involved in this activity?

- How does your child interact with other family members?

- Does your family watch V? Will your child watch TV?

- What does he like to watch? How long will he watch TV?

- Do you have a favorite show?

- Is there anything you would like to do in the evening but can't?

\section{Notes}

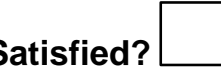

\section{Notes}




\section{Bath time}

- What is bath time like?

- Who usually helps your child bathe?

- How is she positioned in the bathtub?

- Does she like the water? How do you know?

- How involved is your child in bathing herself or playing in the water?

- Does she kick or splash in the water?

- What toys does she like to play with in the tub?

- How does she communicate with you? What do you talk about?

- Is bath time usually a good time? If not, what would make it better?

\section{Satisfied?}

\section{Nap/Bed time}

\section{Home}

- How does bed time go?

- Who usually puts your child to bed?

- Do you read books or have some type of ritual at this time?

- How does he fall asleep?

- How does your child calm himself?

- Does he sleep through the night? What happens if he wakes up? Who gets up with him?

- Is bedtime an easy or stressful time for your family?

Satisfied?

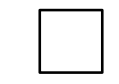

\section{Community Care}

- Does he take naps for other caregivers? How does that go?

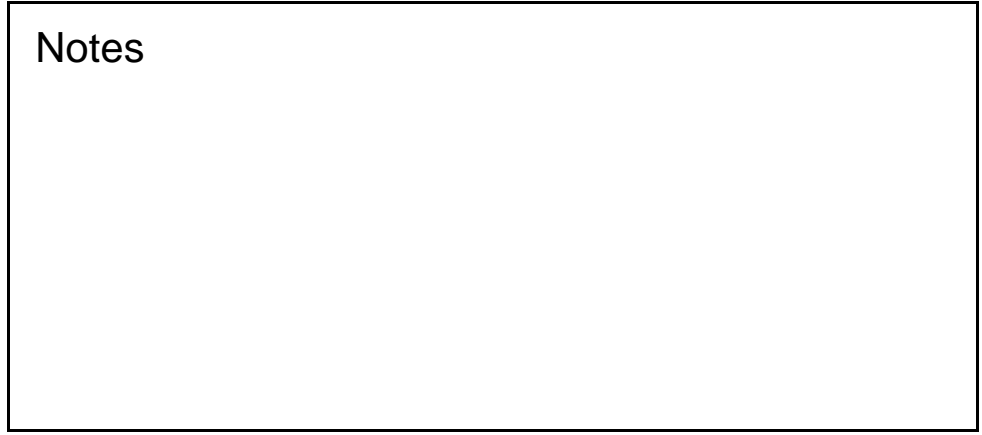




\section{Grocery Store}

- How are trips to the grocery? Do you bring your child with you?

- Does she sit in a shopping cart?

- Does she like being at the store?

- How is she involved in shopping? Do you have to occupy her or is she pretty content?

- How does she react to other people in the store?

- How is she involved in shopping? Do you have to occupy her or is she pretty content?

- How does she react to other people in the store?

- How does she communicate with you and others at this time?

- Is there anything that would make shopping with your child easier?

Satisfied? 


\section{Outdoors}

- Does your family spend much time outdoors? What do you do?

- What does your child do?

- $\quad$ Does your child like (the activity)?

- How does he get around?

- How does he interact with others?

- Are there any toys or games he engages with/in?

- How does your child let you know when he wants to do something different?

- What things does your child like or notice outside?

- $\quad$ Is this usually an enjoyable time? Would anything help make this time easier?

\section{Satisfied?}

\section{Community Care}

- What kinds of outdoor activities doe she participate in? How

Notes much assistance does he need? How does he interact with his peers?

Satisfied? 


\section{Appendix D}

The Parental Stress Scale

\section{Parental Stress Scale}

The following statements describe feelings and perceptions about the experience of being a parent. Think of each of the items in terms of how your relationship with your child or children typically is. Please indicate the degree to which you agree or disagree with the following items by placing the appropriate number in the space provided.

$1=$ Strongly disagree $2=$ Disagree $3=$ Undecided $4=$ Agree $5=$ Strongly agree

\begin{tabular}{|c|c|}
\hline 1 & I am happy in my role as a parent. \\
\hline 2 & There is little or nothing I wouldn't do for my child(ren) if it was necessary. \\
\hline 3 & Caring for my child(ren) sometimes takes more time and energy than I have to give. \\
\hline 4 & I sometime worry whether I am doing enough for my child(ren). \\
\hline 5 & I feel close to my child(ren). \\
\hline 6 & I enjoy spending time with my child(ren). \\
\hline 7 & My child(ren) are an important source of affection for me. \\
\hline 8 & Having child(ren) gives me a more certain and optimistic view for the future. \\
\hline 9 & The major source of stress in my life is my child(ren). \\
\hline 10 & Having child(ren) leaves little time and flexibility in my life. \\
\hline 11 & Having child(ren) has been a financial burden. \\
\hline
\end{tabular}




\begin{tabular}{|l|l|l|}
\hline 12 & It is difficulty to balance different responsibilities because of my child(ren). & \\
\hline 13 & The behavior of my child(ren) is often embarrassing or stressful to me. & \\
\hline 14 & If I had it to do over again, I might decide not to have child(ren). & \\
\hline 15 & $\begin{array}{l}\text { I feel overwhelmed by the responsibility of being a parent. } \\
\text { life. }\end{array}$ & \\
\hline 17 & \begin{tabular}{l} 
I am satisfied as a parent. \\
\hline 18
\end{tabular} & \begin{tabular}{l} 
I find my child(ren) enjoyable. \\
\hline
\end{tabular} \\
\hline
\end{tabular}

